Gut, 1987, 28, 113-116

Leading article

\title{
Immunotherapy for cancer: the use of lymphokine activated killer (LAK) cells
}

The inability of the tumour bearing host to mount an immune response sufficient for the lysis of significant numbers of tumour cells has long been the stumbling block for those interested in the immunotherapy of cancer. Therapeutic approaches designed to immunise the host against putative tumour antigens have been generally unsuccessful. ${ }^{12}$ Attempts to boost immune responses with general immunostimulants have failed, largely because of their lack of specificity and the general paucity of immune responses produced in the tumour bearing host. ${ }^{12}$

The development of 'passive' immunotherapy whereby previously sensitised antibodies or cells ('adoptive' immunotherapy) 3 (-5 are capable of mediating antitumour responses on transfer to a host, represented an attractive alternative to previous therapies for several reasons. This readymade approach would overcome the problems of host immunoincompetence, offer high specificity and could be combined with other therapeutic modalities. ${ }^{1-5}$ One handicap was the relative inability to generate large numbers of sensitised, preferably syngeneic cells, suitable for transfer. ${ }^{1-5}$

The first step forward came in 1980 when Rosenberg and colleagues described a novel method for generating large numbers of lymphoid cells which, after exposure to interleukin-2, were capable of lysing fresh, noncultured primary and metastatic cancer cells. ${ }^{6-8}$ These lymphokine activated killer (LAK) cells are functionally distinct from the population of natural killer cells, because they can lyse tumour cells previously shown to be resistant to natural killer activity. ${ }^{36}$ Furthermore, they are specific for tumour cells and have little, if any, activity against normal cells. ${ }^{3-8}$ Killer activity is not Major Histocompatibility Complex restricted being maintained against non-immunogenic, allogeneic as well as syngeneic tumours. ${ }^{3}$

The next step came in 1983 when Taniguchi and colleagues, using recombinant techniques, cloned the gene for interleukin-2 in a (JURKAT) cell line. ${ }^{9}$ Shortly afterwards Rosenberg et al produced interleukin 2 from $E$ coli as well as the JURKAT cell line. ${ }^{10}$ These manoeuvres allowed large quantities of pure product to be used.

Intravenous administration of large numbers of LAK cells in combination with interleukin-2 (alone neither is very effective) was shown to decrease the number and size of a variety of secondary tumours in the liver and lungs in several murine and guinea pig tumour model systems ${ }^{1-811}$ : similar results have been reported with preliminary studies in man. ${ }^{12}$ Eleven of 25 patients with various types of pulmonary or hepatic metastases exhibited objective remission (a greater than $50 \%$ reduction in tumour volume) after one to three cycles of therapy given over two to three weeks. ${ }^{12}$

In these studies, LAK cells were produced from the peripheral blood of the tumour bearing host by harvesting the mononuclear fraction using 
leucopheresis. This appeared to be moderately well tolerated and was repeated at regular intervals during therapy to maintain the supply of fresh LAK cells. ${ }^{12}$

Further examination of these activated cells in vitro, showed that mature LAK cells represent at least two subpopulations, based on the presence or absence of the differentiation antigen CD 16 (Leu 11). ${ }^{13-16}$ Anti-CD16 recognises the Fc receptor for IgG expressed on natural killer cells. Most LAK cells are positive for this marker and all bear another differentiation antigen, Leu 19 that also identifies the natural killer cell population. ${ }^{16}$ They are all characteristically negative for markers such as CD3 and CD5 that identify $T$ cell subsets and never acquire $T$ cell antigens as a consequence of culturing in the presence of interleukin- $2 .{ }^{16}$

Some peripheral blood $\mathrm{T}$ cells also carry the Leu 19 marker but are apparently not effective in lysing NK-resistant tumour cells even after stimulation with interleukin-2. ${ }^{16}$ There is a difference between these cells and Leu 19 positive T cells derived from lymphoid tissues, however, such as spleen, lymph nodes, or thymus. The tissue-derived T cells show LAK activity against tumour cells ${ }^{16}$ possibly reflecting differences in sensitivity and/or number of receptors on lymphoid cells for interleukin-2.

The success of adoptive therapy with LAK cells in all murine model systems to date has depended on the continued presence of interleukin-2 after transfer to the host. ${ }^{311}{ }^{17}$ Other lymphokines such as interleukin-1 are without effect and irradiation before transfer abrogates the lytic activity of LAK cells, suggesting that continued proliferation may be important in maintaining activation. ${ }^{311}$ High doses of interleukin-2 alone can achieve some decrease in numbers of malignant foci, but this is never as complete as that seen with the combination of LAK cells and interleukin-2. ${ }^{311}$ This suggests that such natural killer cells as may be present in the tumour in vivo are poorly responsive to interleukin- 2 in this environment.

More recently, Rosenberg and colleagues have shown that a subpopulation of lymphocytes that infiltrate tumours (tumour-infiltrating lymphocytes: TILs) ${ }^{18}$ can be expanded, in vitro, in the presence of interleukin-2 to numbers sufficient to cause regression of a variety of advanced metastatic lung and liver tumours in their mouse models. Whether these TILs are identical to the LAK cells generated from peripheral blood is not yet known, although they seem to be more effective in adoptive immunotherapy in these animal models. ${ }^{18}$ While the generation of TILs may be a useful advance, several problems will need to be overcome before clinical trials can begin. These include the acquisition of large enough tumour samples from which to isolate sufficient numbers of TILs, and the long term culture required to generate sufficient numbers of cells for infusion in vivo.

Interestingly, successful therapy with either LAK cells or TILs in mice has been shown to be dependent upon 'immunosuppression' of the tumour bearing host at the time of adoptive transfer by prior treatment of the host with total body irradiation, ${ }^{311}$ or with cyclophosphamide.$^{18}$ In the irradiated mouse, high dose interleukin-2 alone did not cause any significant reduction in tumour load whereas it had some effect in the non-irradiated animals. ${ }^{3918}$ In contrast, successful therapy was maintained when LAK or TILs were added to the interleukin infusion even with prior total body irradiation. ${ }^{3111819}$ Prior treatment of mice with cyclophosphamide enhanced 
the effects therapy with TILs but not LAK cells on tumour cell lysis. ${ }^{18}$ As cyclophosphamide, in addition to a wide range of immunosuppressive effects, can also act as an immunostimulant by abrogating the effects of $\mathrm{T}$ suppressor cells, these results may indicate that removal of host 'suppressive' influences could be an important prerequisite in optimising the effects of adoptive immunotherapy, at least for the TIL cell model. Such inhibitory host effects may also explain why there is such a poor induction of lytic cells in vivo with administration of exogenous interleukin-2 alone. ${ }^{311} 18$ The nature of these 'blocking' factors is unclear but this is obviously one area of exploration which could provide information of considerable importance.

One major limitation of $\mathrm{LAK} /$ recombinant interleukin-2 therapy has been its toxicity. Side effects with systemic administration of recombinant interleukin-2 in man are common and include malaise, fever, chills, headaches, nausea, vomiting, rashes, and fluid retention ${ }^{20-23}$ and these can be expected in over $25 \%$ of patients. ${ }^{12}$ Respiratory distress syndrome in man, ${ }^{12}$ hepatotoxicity and vasculitis have been reported in rodents. ${ }^{20}$ One way in which these problems may possibly be reduced is to administer lower doses of interleukin-2 with LAK cells by continuous infusion into selective sites. This would seem an ideal approach for solitary lesions of the lung and liver where LAK cells tend to accumulate..$^{2124}$ With respect to the treatment of liver tumours, selective administration of LAK cells with interleukin-2 via a catheter inserted into the hepatic artery, ${ }^{26}$ should be an effective route of delivery which might limit side effects. The results of clinical trials are awaited with interest, but it is already clear from the paper by Hsieh and colleagues in this issue of $G u t,{ }^{27}$ that hepatocellular carcinoma can be added to the list of tumours which are susceptible to cytolysis by LAK cells, at least in vitro.

Liver Unit,

ELIZABETH A FAGAN AND ADRIAN L W F EDDLESTON

King's College Hospital,

Denmark Hill,

London SE5 8RX.

\section{References}

1 Terry WD, Rosenberg SA. Immunotherapy of human cancer. New York: Elsevier/North Holland, 1982.

2 Rosenberg SA. The adoptive immunotherapy of cancer: accomplishments and prospects. Cancer Treat Rep 1984; 68: 233-55.

3 Lafreniere R, Rosenberg SA. Successful immunotherapy of murine experimental hepatic metastases with lymphokine-activated killer cells and recombinant Interleukin 2. Cancer Res 1985 ; 45: 3735-41.

4 Borberg H, Oettgen HF, Choudry K, Beattie EJ. Inhibition of established transplants of chemically induced sarcomas in mice by lymphocytes from immunised donors. Int J Cancer 1972; 10: 539-47.

5 Smith HG, Harmel RP, Hanna MG, Zwilling BS, Zbar B, Rapp HJ. Regression of established intradermal tumours and lymph node metastases in guineapigs after systemic transfer of immune lymphoid cells. J Natl Cancer Inst 1977; 58: 1315-22.

6 Yron I, Wood TA, Spiess PJ, Rosenberg SA. In vitro growth of murine T cells. V. The isolation and growth of lymphoid cells infiltrating syngeneic solid tumors. J Immunol 1980; 125: $238-45$.

7 Lotze MT, Grimm E, Mazumder A, Strausser JL, Rosenberg SA. In vitro growth of cytotoxic human lymphocytes. 1V. Lysis of fresh and cultured autologous tumor by lymphocytes in T cell growth factor (TCGF). Cancer Res 1981; 41: 4420-5. 
8 Grimm EA, Mazumder A, Zhang HZ, Rosenberg SA. The lymphokine activated killer cell phenomenon: lysis of NK resistant fresh solid tumour cells by IL-2 activated autologous human peripheral blood lymphocytes. J Exp Med 1982; 155: 1823-41.

9 Taniguchi T, Matsui H, Fujita T et al. Structure and expression of a cloned cDNA for human interleukin-2. Nature 1983; 302: 305-10.

10 Rosenberg SA, Grimm EA, McGrogan M et al. Biological activity in recombinant human interleukin-2 produced in E coli. Science 1984; 223: 1412-5.

11 Mule JJ, Shu S, Rosenberg SA. The anti-tumor efficacy of lymphokine-activated killer cells and recombinant interleukin 2 in vivo. J Immunol 1985; 135: 646-52.

12 Rosenberg SA, Lotze MT, Muul LM, et al. Observations on the systemic administration of autologous lymphokine-activated killer cells and recombinant interleukin-2 to patients with metastatic cancer. $N$ Engl J Med 1985; 313: 1485-92.

13 Grimm EA, Ramsey KM, Mazumder A, Wilson DJ, Djeu JY, Rosenberg SA. Lymphokine-activated killer cell phenomenon. II. Precursor phenotype is serologically distinct from peripheral $\mathrm{T}$ lymphocytes, memory cytotoxic thymus-derived lymphocytes and natural killer cells. J Exp Med 1983; 157: 884-97.

14 Lanier LL, Benike J, Phillips JH, Engleman EG. Recombinant interleukin 2 enhanced natural killer cell-mediated cytotoxicity in human lymphocyte sub-populations expressing the Leu 7 and Leu 11 antigen. J Immunol 1985; 134: 794-801.

15 Itoh K, Tilden AB, Kumagai K, Balch CM. Leu 11+ lymphocytes with natural killer (NK) activity are precursors of recombinant interleukin 2 (rIL-2)-induced activated killer (AK) cells. J Immunol 1985; 134: 802-7.

16 Donohue JH, Rosenberg SA. The fate of interleukin-2 after in vivo administration. $J$ Immunol 1983; 130: 2203-8.

17 Phillips JH, Lanier LL. Dissection of the lymphokine activated killer phenomenon. Relative contribution of peripheral blood natural killer cells and T lymphocytes to cytolysis. J Exp Med 1986; 164: 814-25.

18 Rosenberg SA, Spiess P, Lafreniere R. New approach to the adoptive immunotherapy of cancer with tumor-infiltrating lymphocytes. Science 1986; 233: 1318-21.

19 Mule JJ, Rosenstein M, Shu S, Rosenberg SA. Eradication of a disseminated syngeneic lymphoma by systemic adoptive transfer of immune lymphocytes is dependent upon a host component(s). Cancer Res 1985; 45: 526-31.

20 Matory YL, Chang AE, Lipford EH, et al. Toxicity of recombinant human interleukin-2 in rats following intravenous infusion. J Biol Response Modif 1985; 4: 377-90.

21 Mazumder A, Eberlein TJ, Grimm EA, et al. Phase I study of the adoptive immunotherapy of human cancer with lectin activated autologous mononuclear cells. Cancer 1984; 53: 896-905.

22 Rosenberg SA. Immunotherapy of cancer by the systemic administration of lymphoid cells plus interleukin-2. J Biol Response Modif 1984; 3: 501-11.

23 Lotze MT, Robb RJ, Sharrow SO, Frana LW, Rosenberg SA. Systemic administration of interleukin-2 in man. J Biol Response Modif 1984; 3: 475-82.

24 Lotze MT, Matory YL, Effinghausen SE, et al. In vivo administration of purified human interleukin-2. II. Half-life, immunologic effects and expansion of peripheral lymphoid cells in vivo with recombinant IL-2. J Immunol 1985; 135: 2865-75.

25 Lotze MT, Line BR, Mathisen DJ, Rosenberg SA. The in vivo distribution of autologous human and murine lymphoid cells grown in T cell growth factor (TCGF). Implications for the adoptive immunotherapy of tumors. J Immunol 1980; 125: 1487-93.

26 Okuno K, Takagi H, Nakamura T, Nakamura Y, Iwasa Z, Yasutomi M. Treatment for unresectable hepatoma via selective hepatic arterial infusion of lymphokine-activated killer cells generated from autologous spleen cells. Cancer 1986; 58: 1001-6.

27 Hsieh KH, Shu S, Lee CS, Chu CT, Yang CS, Chang KJ. Lysis of primary hepatic tumours by lymphokine activated killer cells. Gut 1987; 28: 117-24. 